\title{
ÇEVRE SORUNLARININ ÇÖZÜMÜNDE COĞRAFYANIN ROLÜ
}

\author{
Dr. Recep EFE \\ Fatih Üniversitesi, Fen-Edebiyat Faküitiesi, Coğrafya Bölümü, Doçent
}

\begin{abstract}
Geography can be described as 'the study of the earth in terms of human activity'. Geography is a bridge between the humanities and the sciences. It has always been a generalized as opposed to a specialized discipline, so that its viewpoint is toward to broad understanding. There is a very delicate balance between the human and physical environment. This balanced relationship can be spoiled easily if one interferes with the other. Geography aims to establish peace and balance between man and nature and to help them live together in harmony.
\end{abstract}

\section{I-GIRIS}

Yeryüzü ve insanı birbirinde ayrı düşünmek imkansızdır. Yeryüzü genel anlamda cansız bir varlık gibi düşünülse de aslında o bünyesinde sayısız canlıyı barındırmaktadır. İnsansız bir yeryüzünden bahsettiğimiz zaman bile yeryüzünde yaşayan bitki ve hayvanlar onun önemini arttırır. Yerküre insansız yaşayabilir. Fakat insan onsuz yapamaz. İnsanın bastığı yer, taş, toprak, nefes aldığı hava, içtiği su, ekip biçtiği toprak, etrafındaki bitki ve hayvanlar; bunların hepsi veryüzünün birer parçasıdır. Bütün bunlar aynı yerde bir arada bulunur. Bu unsurlarm birbirine zarar vermeden aynı ortamı kullanması ekolojik denge sayesinde olmaktadır. Yeryüzünde canlı ve cansız varlıkların bir arada bulunduğu bir çok ekosistem vardır. Dünyamızın kendisi en büyük ekosistem yani Ekosfer'dir (Ecosphere).

\section{II- COĞRAFYA NEDIR?}

Coğrafyanın bir çok tanımı yapılabilir. Fakat "İnsan etkinlikleri açısından yeryüzünün incelenmesi" tarifi bunların çoğunu bir araya getirmektedir[1]. Yeryüzü fiziksel bir ortam olup bunun üzerinde yaşayan insan ise ona kültürel özellikleri kazandıran bir varlıktır. İnsan ile yeryüzü arasında çok sıkı bir iletişim ve etkileşim vardır. İletişim karşılıklıdır fakat faydalanma tek yönlü olmaktadır. İnsan yeryüzünden faydàlanırken ona verdiği bir şey yoktur. Bu nedenle kendisini sunulan bu imkanı çok iyi değerlendirmek zorundadır.

\section{III-COĞRAFYA VE ÇEVRE}

Insan yaşadığı ortamı bildiği ölçüde ondan faydalanabilir. Yeryüzünü daha iyi tanımamıza yardımcı olan coğrafya günümüzde yaşadığımı ortamla ilgili meselelerin çözümünde etkili olarak kullanılmaktadır. İnsan ile yeryüzü arasındaki ilişkileri en güzel şekilde düzenleyen bu bilim dalının pratikte kullanılması toplumda iyi coğrafya eğitimi almış insanların artmasına bağlıdır. Bütün dünyada olduğu gibi Türkiye'de de insan ile çevre ilişkilerindeki dengenin bozulmasından kaynaklanan problemler vardır. Coğrafyanın gerek beşeri ve gerekse fiziki ortamda daha etkili olarak kullanılamamasının nedeni coğrafya eğitiminin yetersiz olmasından kaynaklanmaktadır. Coğrafya bilgisinin "Insan etkinlikleri açısından yeryüzünün incelenmesi" tarifine uygun olarak algılanması halinde bir çok meseleye çözüm üretebildiği görülür.

Günümüzde gerek fiziki ve gerekse beşeri dünyanın en büyük problemi çevre bozulmasıdır. Yeryüzünde hava, toprak ve su kirliliği hızla artmakta, canlılar (insan, hayvan, bitki) için çok önemli olan toprak akarsular vasitasıyla göl ve denizlere taşınmaktadır. Insanlar yakacak ve yapı malzemesi temini gibi nedenlerle bitki örtüsünü tahrip etmektedir. Şehirlerde aşırı nüfus artışı ve göç nedeniyle çarpık yerleşmeler çoğalmaktadır. Hızlı artan nüfus, plansız büyüme ve trafik problemi günden güne içinden çıkılmaz hale gelmektedir. Yeryüzünde ve yurdumuzda nüfusun yarıșndan fazlasınin yaşadığı kıyı alanları hızla bozulmaktadır.

Çevre ve Çevre sorunları günümüzde insanların çok sık kullandıkları terimlerdir. Fakat her insan "çevre sorununu" farklı düşünmektedir. Bazıları için kirli deniz, soluduğumuz kirli hava, bazıları için de yere atılan kağıtlar birer çevre sorunudur. Kimileri için de çevre sorunu fosil yakıtların yakılmasıly atmosferde biriken $\mathrm{CO}^{2}$ in yol açabileceğ $\mathrm{iklim}$ değişiklikleridir. Kısaca çevre sorunlarına bir çok örnek verilebilir ve örnekler herkese, her meslekten insana göre farklı farklı olacaktır. Çünkü çevre yaşadığımız yeryüzüdür. Çevre sorunu da yeryüzü ile insan arasında meydana gelen iletişim bozukluğudur. Coğrafya ise yeryüzünün tanımlanması, yeryüzü ile insan arasındaki ilişkilerịn tarifi olduğuna göre coğrafya bir çevre bilimidir. Çevre sorunlarını tespit etmek ve bunlara çözüm yolları bulmak için çevrenin çok iyi tanınması gerekir. Çevrenin bilinmesi ve tanınması iyi bir coğrafya bilgisi sayesinde çok daha kolay olur. Çünkü coğrafya evrendeki canlı ve cansız bütün varlıkları incejer. Coğrafya incelemeye tarifle başlar, daha sonra sinıflama ve gruplama yaptıktan sonra analiz ve sentez yaparak yorum ve açıklama getirip konuyu tamamlar. Yani "Ne nerededir? sorusuna cevap aramaktan çok "O"nun niçin, nasıl ve neden orada olduğu sorusunun cevabinı verir.

İnsanoğlu yeryüzünde yaşamaya başladığından bu yana çevresiyle ilişki halinde olup onu hep kendi menfaati 
için değiştirmeye çalışımıştır. Toprağın aşırı kullanılması, ormanlarmn tahribi bunun en çarpicı örnekleridir. Avrupa'da başlayan sanayi devrimine kadar insanın yeryüzüne müdahalesinin etkilerinin olumsuz sonuçları pek fazla ortaya çıkmamıştır. Yani yüzlerce hatta binlerce yıldır ekosistem kendi kendini bir ölçüde yenileyebilmiştir. Daha sonra doğal bitki örtüsünün tahribinin hızlanması, havanın ve suların kirlenmesi insan ile yeryüzü arasındaki hassas dengenin bozulmasına neden olmuştur.

İnsanın yeryüzü ile ilişkileri coğrafyanın ele aldığı konuların temelini oluşturur. Çünkü yeryüzünde gördügüüüz canlı ve cansız her şey insan ile ilişki halinde olup bu ilişkinin ahenk ve denge içinde sürmesi gerekmektedir. Uyumun bozulması bazen ilk planda tabiat aleyhine gözüken fakat sonuçta insanm aleyhine olan ve bazen geç fark edilen sonuçlar ortaya çıkarır ki biz bunlara çevre somularl diyoruz.

Canlı varlıkların hayati bağlarla bağlı oldukları, etkiledikleri ve etkilendikleri mekan birimlerine 0 canlının veya canlılar topluluğunun yaşam ortamı "Çevre" denir. bu mekan birimleri birbiriyle ilişkili canlı ve cansız unsurlardan oluşan, madde ve enerji dolaşımı ile kendini besleyen bir ekosistemdir. Bir orman, bir köy, akarsu, şehir birer ekosistemdir. Bunların toplamı ise tüm dünyayı kapsadığından dünyanın bütününü de bir ekosistem olarak ele alabiliriz.

Çevremizde bulunan nehir, göl yada yerleşim yerleri coğrafi öğeler olan iklim ve bitki örtüisü ile yakından ilgilidir. Yağışın miktarı ve şekli, bitki örtüsünün sıklığı, ya da yeraltı suları akarsuları doğrudan ya da dolaylı olarak etkiler. Topoğrafyanın özellikleri, bitki örtüsünün sık ve seyrek oluşu yada hiç olmaması, yağışla düşen suyun ne kadarmın akıșa geçtiği ve ne kadarının toprak tarafından emilerek yeraltı suyuna karıştığı veya kaç metreküp suyun buharlaşma ile kaybolduğu çevre açısından çok önemlidir. Bitki örtüsünde, iklimde ya da topoğrafyada yani ekosistemlerde meydana gelebilecek herhangi bir olumsuz değişme çevre sorunu olarak karşımıza çıkmaktadır. Yeryüzünde bulunan ekosistemlerde değişiklikler bazen olumlu da olabilir. Bu durumda herhangi bir problem doğmaz. Sadece olumsuz değişimlerde denge insan aleyhine bozulduğu için problemler ortaya çıkar. Çevre sorunları sadece kirlilik değildir. Bitkilerin tahrip edilmesi, canlı türlerinin azalması, doğal kaynakların tükenmesi, sulak alanların göllerin ve akarsuların kuruması, kaynak sularının kaybolması, verimli tarım alanların in meskenlerle ya da sanayi tesisleriyle dolması, şehirlerde görülen çarpık ve plansız yapılaşma, yoğun trafik, gürültü vs. hepsi birer çevre sorunudur[2].

Bütün bu sorunların farkına varmamız için ve bunları iyi analiz ederek kalıcı ve etkin çözümler üretebilmemiz için yaşadığımı ekosistemi yani yeryüzünü tanımamiz gerekir. Bir cografyacı olarak bu tanımayı nelerin nerede olduğu şeklinden ziyade bunların neden orada olduğu niçin başka yerlerde olmadığı yada olamayacağı üzerinde dikkatle durulması gereken konulardır. Ömeğin bir tarım ürününün nerelerde yetiştiği bunun dünyanın başka yerlerinde yetişmemesinin nedenleri, Türkiye'de niçin Karadeniz bölgesinin İç Anadolu bölgesine göre daha gür bir bitki

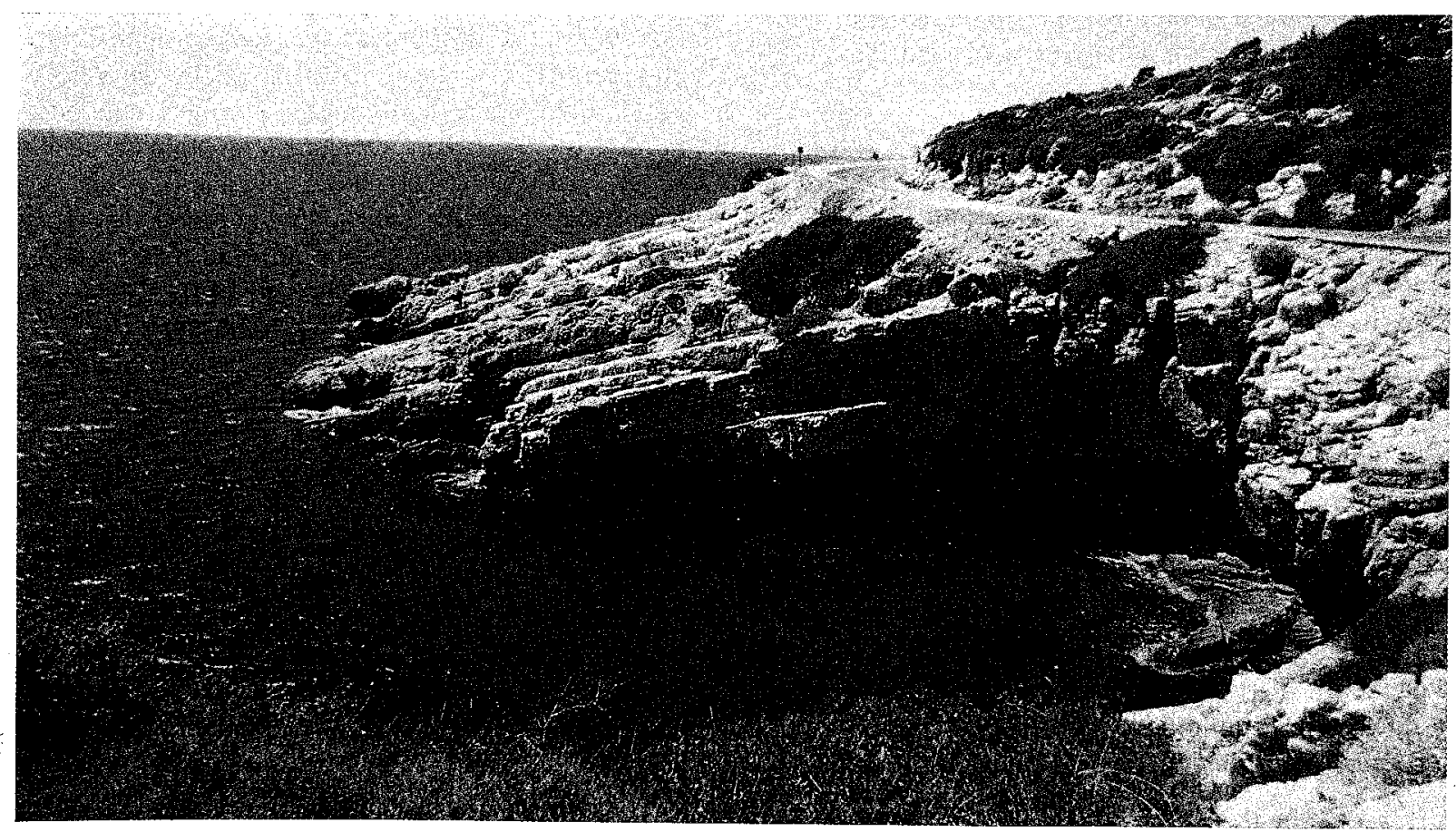

Foto 1: Çevrenin unsurları olan litosfer (kıyıdaki kayalar), atmosfer (gökyüzü), hidrosfer (deniz) ve biyosferin (bitki örtüsü) birleştiği doğal ortam. Yeryüzündeki bu dört küre bir çok yerde birbiriyle etkileşim halindedir. 

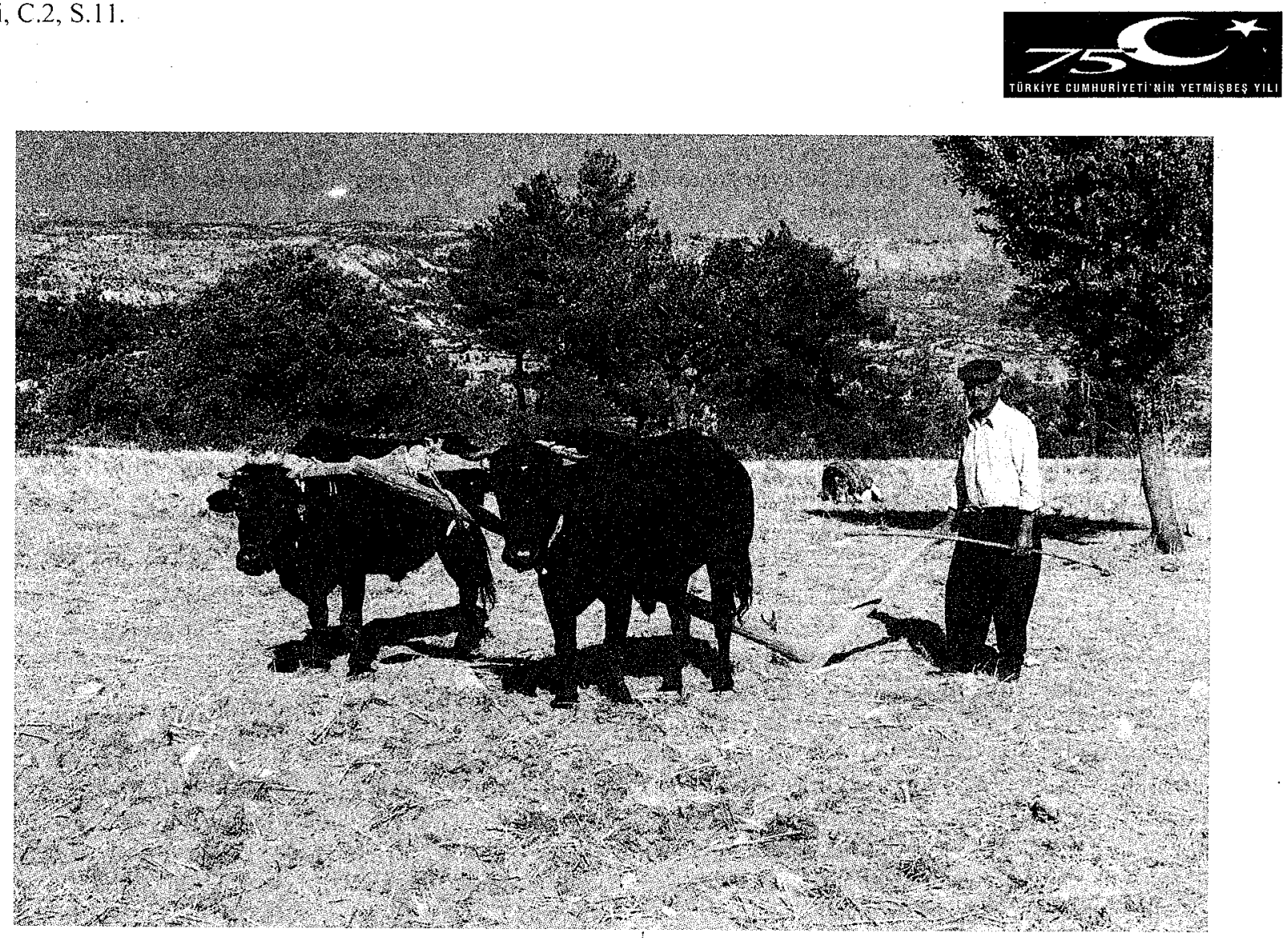

Foto 2: Çevrenin önemli unsurlarından olan insan yeryüzünden çok değişik şekilde faydalanmaktadır.

örtüsüne sahip olduğu gibi konuları coğrafya bilgisi sayesinde an lamak çok kolaydır.

Tarihi çağlarda ve günümüzde yerleşim birimlerinin çoğu su kenarlarına kurulmuştur. Uygarlıklar verimli tarım alanları çevresinde gelişmiştir. Savunmanın büyük önem kazandığ dönemlerde engebeli ve yüksek yerlere kurulan şehir devletleri verimli tarm alanlarından ve sudan uzak değildi. Bergama, Milet, Efes, Truva bunun en iyi örnekleridir. Bunların her biri yüksek bir sahada kurulmuştur. Bergama Bakırçay'a, Milet Küçük Menderes'e, Efes Büyük Menderes'e Truva ise Kara Menderes nehrine yakın bir konumda kurulmuştur.

Çünkü bu nedenler iyi analiz edilerek ortaya konulduğu takdirde ne zaman dengenin bozulabileceği ve sonuçta insanın ne gibi problemlerle karşı karşıya kalacağı çok daha iyi anlaşılır. Bu sayede insanın daha fazla ürün elde edebilmesi için tarım ilacı ve yapay gübre kullanması, sanayi tesislerinden çıkan katı ve Sıvı atıkların akarsu, göl ve denizlere bırakılmasının nasıl sonuçlar doğuracağı daha kolay anlaşılmış olur. Tarım alanlarında kullanılan yapay gübre ve kimyasal ilaçların toprakta ne gibi değişikliklere yol açabileceğini anlamak için toprağı tanmmak gerekir. Toprak, içinde çok miktarda canlının yaşadığı bir ekosistemdir. Toprak içinde barınan canlı organizmaların ve bakterilerin ölmesine yol açan bu ilaçlar toprağın verimliliğinin zamanla yok olmasına yol açar. Yine aynı kimyasal hammaddelerin topraktan yeraltı suları vasıtasıyla akarsulara oradan da göl ve denizlere ulaşarak buraları kirlettiği bir gerçektir. Ayrıca bu ilaçlar kullanılarak yetiştirilen ürünler büyüme sırasında topraktan aldığ mineral ve tuzlar vasitasıyla bu zararlı kimyasal maddeleri de bünyelerine alır. Bu bitkiler insanlar tarafından kullanıldığında insanların sağlık problem leri ile karşı karşıya kaldıkları da bilinmektedir.

İklimi değiştiren fosil yakıtlar yerine nükleer enerji kullanılırsa yeryüzündeki hayatı tehdit eden çevresel problemlerin ortadan kalkacağı fikri ileri sürüldü. Fakat çok geçmeden nükleer enerji kullanimından kaynaklanan radyoaktif maddelerin atmosferde önemli bir kirliliğe neden olduğu anlaşıldı. Yeryüzünde çevre sorunlarına neden olan etkenlerin tamamı antropojendir. Yani bunların hemen hemen hepsi insan tarafindan meydana getirilmektedir. Mesken ve sanayi tesislerin bacalarından çıan dumanların havayı kirletmesi, akarsu, göl ve denizlerin kirlenmesi, tarım alanlarının kullanılamaz hale gelmesi, toprakların verimliliğinin azalması, ormanların tahrip edilmesi, çölleşme, kuraklık, kıtlık, şehirlerdeki çarpık yapılașma, gürültü gibi bütün problemler insandan kaynaklanır.

Hava kirliliğinin önemli bir sonucu da atmosfer ısısınin artmasıyla ortaya çkan sera etkisi (green house effect) tir. Fosil yakıtların yakılmasıyla havada biriken $\mathrm{CO}_{2}$ 
dünyaya gelen güneş ışınlarını azaltır ve aynı zamanda da yeryüzünden yansıtılan ışınları da emerek atmosferin daha fazla isınmasina neden olur. Yapılan araştırmalar kirliliğin bu hızla devam ettiği taktirde havadaki $\mathrm{CO}_{2}$ miktarı 21. yüzyıl ortalarında şimdikinin iki katına çıkacağı ve bunun sonucu da ısının ortalama $2{ }^{\circ} \mathrm{C}$ artarak dünya ikliminin değişeceğini ortaya koymaktadır. İklimde meydana gelen bu değişim sıcaklığın artması sonucu yeryüzündeki buzulların büyük bir kısmının erimesine ve alçak kıyıların sular altında kalmasına yol açacaktır.

Yerleşim yerlerindeki kanalizasyonların ve sanayi tesislerinin atık suları çevredeki akarsu, göl veya denizlerde önemli kirliliğe yol açmaktır. Göl ve akarsular insanların önemli su kaynaklarıdır. Bu suların insanlar tarafindan kullanılamaması büyük çevre sorunlarına yol açmaktadır. Dikkat edilmediği takdirde çevrenin kirlenmesi çok zaman almaz. Örneğin 1 litre ham petrolün 1 milyon $\mathrm{m}^{3}$ temiz suyu kirlettiği tespit edilmiştir. Suların kirlenmesi, akarsu, göl deniz ve okyanuslarda yaşayan hayvanların temel gidasını oluşturan planktonların yok olmasına neden olmakta ve bunun sonucunda bu sularda yaşayan balık ve diğer canlı türleri azalmaktadır. Ayrıca atmosfere önemli miktarda $\mathrm{O}_{2}$ sağlayan sular kirlendiği için bu işlevlerini yerine getiremez duruma gelmektedir[3]. Burada ortaya çıkan önemli bir konu, havanın kirlenmesi suların kirlenmesine yol açarken, suların kirliliği de havanın kirlenmesine neden olmaktadır. Yani döngüdeki bir zincirin halkasının kopmasıyla ekolojik dengenin bütünü bozulmakta ve yeryüzünde yaşayan canlıların tamamı bundan etkilenmektedir.

Bitki örtüsünün tahribi ile ortaya çıkan erozyon toprağın zamanla kaybolmasına yol açarak yiyecek temini güçlüğü ve sonuçta kıtlık ve açlık gibi sosyoekonomik problemler doğurur. FAO (Dünya Gıda ve Tarım Örgütü) raporuna göre bugün dünya üzerinde ekilebilir 3.2 milyar hektar arazinin ancak yarısı şu an kullanılabilir durumdadır. Diğer yarısı çeşitli çevre problemleri nedeniyle ekilememektedir. Bunların kullanılabilir hale getirilmesi de hemen hemen imkansız görülmektedir. Yani bu toprakları ıslah etmenin maliyeti çok yüksektir. Bu nedenle bu çözüm yolu ekonomik olmamaktadır. Ayrıca yurdumuzda son yollarda hızlı bir şehirleşme hareketi gözlenmektedir. Verimli tarım arazileri üzerinde kurulu şehirlerimiz ve kasabalarımız hızla genişlemekte ve ekilebilir alanlar, yakın çevrede yer alan ormanlar ve yeşil. alanlar yapılaşma uğruna tahrip edilmektedir. Gerek erozyon, gerek yapılaşma ve gerekse kirlilikle kaybedilen toprağın geri kazanılması kısa vadede mümkün görülmemektedir.

Sanayi devremi ile birlikte insanın geçim ekonomisinden kazanç ekonomisine geçtiği görülür. Insan yeryüzündeki dengeyi ekonomik kaygılar nedeniyle bozmuştur. Ekonomik menfaat, fazla üretim isteği, bencillik ve sömürü insan-yeryüzü ilişkisinin insan aleyhine bozulmasının temel nedenleridir. yapılan üretim kalıcı olmaktan çıkıp geçici amaçla yapılmaya başlanmıştır. Üretim ya da hizmetin ömrü ne kadar kısa olursa o kadar çok üretir ve o kadar çok kazanırım felsefesi ağırlık kazanmıştır. Üretimin artması için tüketimin teşvik edilmesi gerektiği anlaşılmış ve bu yolda büyük çabalar harcanarak hedefe ulaşılmıştır. Toplumda çok tüketme ve iyi bir tüketici olma modernleşme ile aynı an lam kazanmıştır.

Sanayi devrimi ile birlikte dünyanın iler gelen devletleri ve şirketleri daha çok ürün ve gelir elde etmek için önce çevreyi kirletmişler daha sonra da çevreyi temizlemek için gelir elde etme yoluna gitmişlerdir. Yani insanlar çevreyi kirletirken de, temizlerken de hep çok kazanmayı düşünmüşlerdir.

Yeryüzü ile insan arasındaki ilişkilerin bozulması sonucu ortaya çıkabilecek sorunları önceden kestirmek (tahmin etmek) her zaman kolay değildir. Bu nedenle bu ahenk ve dengeyi korumak veya müdahale sonunda ne olabileceğini bilmek için çevreyi yani yaşadığımız köyü, kasabayı, kenti, bölgeyi ve ülkeyi hatta dünyayı tanımamız gerekmektedir. Bunları tanımanın en iyi yolu iyi bir coğrafya bilgisi ile mümkündür. Yeryüzündeki canlı ve cansız her şey insan için vardır. Fakat bunu bilinçsizce kullanmak insanın kendi sonunu yine kendisinin hazırlamasına neden olmaktadır.

Türkiye, insanların neden olduğu bu problemlerin çoğu ile bugün karşı karşıyadır. Bunların çözümü için tek çare eğitim olmasına rağmen buna yeteri kadar önem verilmemektedir. Kalkınmış ülkelerde bu meseleler planlı bir eğitimle çözülmüş ya da çözülmeye çalışılmaktadır. Dünyanın önde gelen ülkelerinde yaşayan insanların gerek fiziki ve gerekse beşeri meselelere karşı duyarlı olmalarının nedeni iyi bir eğitim almalarından kaynaklanır. Bu ülkelerde okutulan coğrafya kitapları ile uygulanan coğrafya eğitim metot ve tekniklerini incelediğimizde insanların yaşadığ ortamda meydana gelen problemlere karşı duyarlı olmalarında coğrafyanın payının çok büyük olduğunu görmekteyiz. Çünkü coğrafya kapsadığı konular ve konuları ele alış tarzı ile yukarıda değindiğimiz bütün meselelerin çözümünde kullanılabilecek bir bilim dalıdır.

Türkiye'de ise birçok kurum ve kuruluş toprak erozyonu başta olmak üzere, çevre kirliliği, su problemi, hava kirliliği, trafik, çarpık yapılaşma, sel, deprem, işsizlik, göç, vs. gibi meselelere çözüm aramakta; tarımsal, endüstriyel kalkınma planları ve formülleri üzerinde durmaktadır. Fakat bunların çoğu, tabana veya geniş kitlelere ulaşmadan problemi çözmeye çalıştıklarından başarılı olamamaktadır. Geniş kitlelere ulaşmanın yolu ise ilköğretimden başlayarak konuyu işlemek bunu coğrafya dersi aracılığı ile bütün eğitim ve öğretim süresince gündemde tutmak ve toplumu bu yolla bilinçlendirmektir. Günümüzde çok büyük önem taşıyan bu meselelerin 
çözümünde; A.B.D, İngiltere, Almanya ve Japonya ile dünyanın belli başlı ülkelerinde olduğu gibi modern metot ve teknikler kullanılarak yapılan bir coğrafya eğitimin ve bilgisinin katkısı göz ardı edilmemelidir.

İnsanoğlunun yeryüzünde yaşamaya başladığından bu insanın çevre ile ciddi boyuttaki ilk ilişkisi tarımla olmuştur. Yirminci yüzyılda ise insan yeryüzündeki karaların hemen hemen tamamını kullanmaya bașlamıştır. Soğuk kutup bölgeleri, çöller, sarp dağlık alanlar ve tropikal orman sahaların dışındaki yerler bugün insanlar tarafından tamamen kullanılmaktadır.

\section{IV-SONUÇ}

Coğrafya insan ve onun yaşadığ 1 yeryüzünü inceler. Yeryüzünü oluşturan birimlerin (hava, su, toprak, taş, bitki, hayvan) dikey ve yatay dağılışlarını ve bunun nedenlerini ortaya koyar. Bu öğeleri tek tek ele almakla kalmaz bunlar arasındaki ilişkileri, ve bunun sonucunda ortaya çıkan yeni durumları da izah eder. Yeryüzü bütün bu doğal ve beşeri özellikleriyle bir çevredir. Doğal varlık ve olaylarla insan arasındaki ilişkiler çevre sorununun temelini oluşturur. İlişkilerin bozulmasıyla çevre sorunları ortaya çıkar. Coğrafya doğal ortam öğeleri arasındaki ilişkilerin ve doğal ortam ile insan arasındaki etkileşimin nasıl olduğunu ortaya koyarken yanlışları da ortaya çıkarır. İnsanın yaşadığı çevrenin kullanım şeklini açıklar. Bu nedenle çevre sorunlarının çözümü çevrenin iyi tanınmasıyla olur. Çevrenin tanınması ise iyi bir coğrafya bilgisi ile olur.

\section{KAYNAKÇA}

[1] EFE, Recep (1997) Coğrafyada Yeni yaklaşımlar, Coğrafya Eğitiminde Çağdaş Metot ve Teknikler. Marmara Coğrafya Dergisi. Sayı 1. s. 135-149, İstanbul.

[2] Mc KNIGHT, T.L. (1993) Physical Geography. University of California. Prentice Hall Publ. U.S.A.

[3] MARSH, W.M., GROSSA, J. (1996) Environmental Geography. Science. Land use. and earth systems. John Wiley \& Sons, Inc. 